\title{
Dominance in monkeys: Early rearing and home environment ${ }^{1,2}$
}

\author{
W. F. ANGERMEIER, JOHN B. PHELPS, AND STEVE MURRAY, FLORIDA PRESBYTERIAN COLLEGE
}

H. H. REYNOLDS, ARL, HOLLOMAN AFB, NEW MEXICO

Dominance tests were performed on 28-30 month old male rhesus monkeys, reared from the age of 2-4 months under four different conditions of perceptual and social enrichment. Results showed: (1) no differences between any of the four groups, except those due to significant differential weight of experimental Ss, and (2) a "group effect" to be operating which was somewhat akin to the social relationship among feral monkeys, generally described in the literature as territory or home range.

In a recent study Uyeno \& White (1967) showed that rats reared in social isolation were inferior to socially reared Ss when paired for an underwater dominance test. It was thought important to obtain data on primates reared under similar conditions. The literature cites a number of dominance studies where the interaction of primates was observed in their natural habitat (Altmann, 1962; Southwick, Beg, \& Siddigi, 1965; Manocha, 1966, among others), but there have been very few dominance tests of rhesus monkeys reared under standard laboratory conditions (1965). Mason (1961) found that dominance relationships of wild monkeys are more stable than those of restricted laboratory Ss.

Two studies on male rhesus monkeys are reported here. Study 1 sought to determine the relationship between dominance status and differential early rearing, and Study 2 was concerned with the relationship between dominance status and home environment. Subjects

Twenty-eight male rhesus monkeys, 28-30 months of age at the time of testing, were used as Ss. Ss were drawn from the following rearing conditions where they had been since the age of 2-4 months: (1) Strict Isolation (SI), an environment which permitted no visual or tactual contact between individual Ss; (2) Partial Isolation (PI), a condition which permitted visual and moderate tactual contact between cage neighbors; (3) Social (S), where two Ss were housed in one cage and visual and moderate tactual contact were permitted between cages; (4) Enriched Social (ES), where animals were treated as in (3) with the additional presence of play objects, swings, and television. The animals had also been used previously in a match-to-sample shock escape task for a period of eight months.

\section{Apparatus}

The dimensions of the wire testing cages in which the animals were paired for dominance fights were $19 \times 20 \times 24$ in. high for Ss weighing less than $12 \mathrm{lb}$ and $21 \times 24 \times 34$ in. high for ss weighing more than $12 \mathrm{lb}$ in Study 1 , and a clear plastic cage set in a metal frame-34 $\times 48 \times 72$ in. - in study 2 . The respective cage was placed in a testing room $9 \times 15 \times$ $8 \mathrm{ft}$ high, where Ss could be observed from an adjacent room through a large one way window.

\section{Procedure}

In Study 1 six animals from each rearing condition were ranked by weight. Only equally ranked Ss from each rearing condition were paired with each other. Animals stayed in the testing cage between 15 and $30 \mathrm{~min}$, the time interval it took to reach unanimous agreement among four observers regarding the outcome of the test.

Each animal was paired with an animal of equal weight rank from a different rearing condition once a day. On Day 1, the animals from Conditions ES and SI, and Conditions S and PI were paired. On Day 2 , the animals from Conditions ES and PI, and Conditions 'S and SI were paired. On Day 3 , the animals from the ES condition were paired with those from the $\mathrm{S}$ condition, and the PI animals were paired with the SI animals.

In Study 2 two animals from one home environment (not cage mates) were paired with one animal from another home environment. A total of nine comparisons, involving three animals each, was made.

\section{Observations}

The following behavioral aspects were observed to be characteristic of the dominant animal: (1) sexual -inspection of genitals, premounting posture, pulling genitals, full erections, mounting, and thrusting, and pulling up rear; (2) aggressive-pushing, shoving, swiping, hitting, biting (particularly head and neck area), threatening head movements in horizontal plane, stalking, circling, pulling tail, ears and skin, and

Table 1. Dominance in Monkeys Reared Differentially

\begin{tabular}{lcccccc} 
& $\begin{array}{c}\text { Average Weight } \\
\text { Group }\end{array}$ & lbs & Weight & \multicolumn{2}{c}{ Dominance Fights } & Dominance \\
\cline { 3 - 5 } & 13.53 & Rank & Won & Lost & Rank \\
\hline PI & 11.88 & 1 & 16 & 2 & 1 \\
S & 11.23 & 2 & 3 & 15 & 4 \\
ES & 11.02 & 3 & 10 & 8 & 2 \\
SI & 11 & 4 & 7 & 11 & 3 \\
\hline
\end{tabular}

Group Comparisons

\begin{tabular}{|c|c|c|c|c|c|c|}
\hline \multirow[b]{2}{*}{ Groups } & \multicolumn{3}{|c|}{ Dominance Difference } & \multicolumn{3}{|c|}{ Weight Difference } \\
\hline & $t$ & $\mathrm{p}$ & Group Favored & 1 & $p$ & Group Favored \\
\hline ES-S & 2.17 & - & ES & 1.33 & - & $\mathrm{S}$ \\
\hline ES-PI & 2.22 & - & $\mathrm{Pl}$ & 9.64 & .001 & $\mathrm{PI}$ \\
\hline ES-SI & $\therefore 1.00$ & - & ES & 1.97 & - & ES \\
\hline S.PI & 5.42 & .01 & $\mathrm{Pl}$ & 2.54 & .05 & $\mathrm{PI}$ \\
\hline S-SI & 1.37 & - & $\mathrm{SI}$ & 2.09 & - & $S$ \\
\hline $\mathrm{PI}-\mathrm{SI}$ & 1.97 & - & $\mathrm{Pl}$ & 4.82 & .01 & $\mathrm{Pl}$ \\
\hline
\end{tabular}


Table 2. The Laboratory Living Environment and Dominance

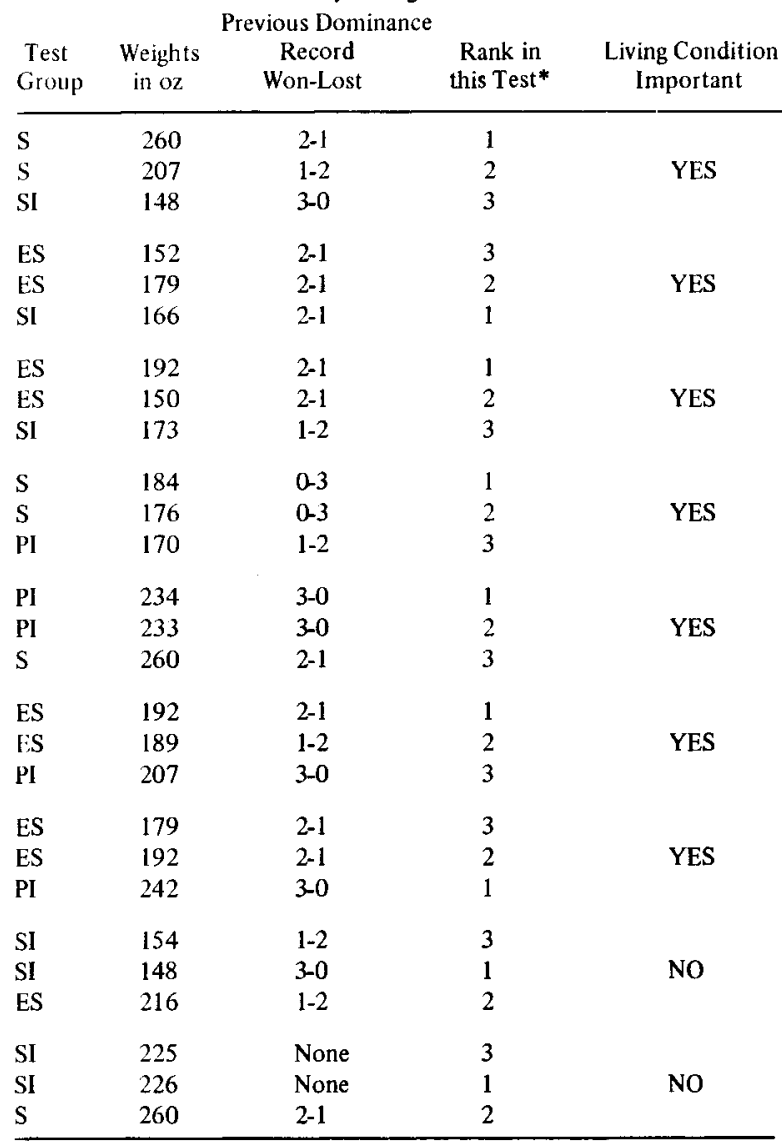

*Rank of 1 is most dominant

grooming; (3) positional-preferred cage position, free movement and dominant posture (with head and tail pointing up). In the same categories, the submissive animal showed opposite behavioral characteristics. Statistical Analysis and Discussion

The results of Study 1 can be seen in Table 1 . In a gross comparison between rearing groups, the PI animals received the highest dominance rating. When $t$ tests for differences between correlated means were computed, only one significant difference between number of dominance fights won was established. This difference occurred between the PI and S animals. When weights (taken before dominance testing began) were compared, it was evident that the PI animals were significantly heavier than the animals from the three other rearing conditions.

It is evident from Table 1 that the rather large average weight differential between the PI animals and the ES, S, and SI animals was responsible for the high dominance rating of the PI group. When the data of the PI group are discarded, no significant differences in number of dominance fights won existed between the ES, S, and SI groups.

The data presented in Study 1 seem to support the conclusion that differential early rearing has no effect upon the dominance status which rhesus monkeys will achieve. This study furthermore points out the importance of considering phylogenetic differences in the area of social relationships, of which dominance is an important aspect.

The results of Study 2 can be seen in Table 2 . It is evident from the data in Table 2 that, for the animals from the ES, S, and PI living conditions, the home environment seemed important during the dominance tests. This was not the case for the animals from the SI condition. The one basic difference between the SI animals and the ES, S, and PI animals was visual interaction with other animals from the same colony. When the binomial test suggested by Siegel (1956) was applied to the number of times home environment was important, the resulting probability was found to be $\mathbf{. 0 0 8}$. Neither weight differential nor origin of the single animal was found to be significant when tested by the binomial test.

The following conclusions seem to be warranted: (1) when two monkeys, living in one home environment, are tested with one monkey from a different home environment, like living condition seems to be the single most important factor in the establishment of dominance; (2) visual (and possibly tactual) experience among the animals of one home environment is important for the development of this "group effect"; (3) this group effect seems to be somewhat akin to the social relationship among feral monkeys, generally described as territory or home range.

\section{References}

ALTMANN, STUART A. A field study of the sociology of rhesus monkeys, Macaca mulatta. Ann. N. Y. Acad. Sci, 1962, 102, $338-435$.

JAY, P. Field Studies in "Behavior of Nonhuman Primates" II, A. M. Schrier, H. F. Harlow, \& F. Stollnitz, (Ed.), Academic Press, New York: 1965. Pp. 525-591.

MANOCHA, S. N. A comparative study of rhesus monkeys and langurs: Free social behavior. Psychol. Stud., 1966, 11, 23-30.

MASON, W. A. The effects of social restriction on the behavior of rhesus monkeys: I. Free social behavior. J. comp. physiol. Psychol., 1960, 53, 582-589.

SIEGEL, S. Nonparametric statistics. New York: McGraw-Hill, 1956. SOUTHWICK, C. H., BEG, M. A., \& SIDDIGI, M. R. A population survey of rhesus monkeys in northern India: II. Transportation routes and forest area. Ecology, 1961, 42, 698.

UYENO, E. T., \& WHITE, M. Social isolation and dominance behavior. J. comp. physiol. Psychol., 1967, 63, 157-159.

Notes

1. This research was supported by AF Contracts AF29(600)-5135 and F29600-67-C-0011 between the Aeromedical Research Laboratory, Holloman AFB, New Mexico and Florida Presbyterian College.

2. A more detailed report is available upon request. 